\title{
Clinical and Radiological Outcomes of a New Cage for Direct Lateral Lumbar Interbody Fusion
}

\author{
Shin Jae Kim¹, Young Seok Lee', Young Baeg Kim¹, Seung Won Park', Vo Tan Hung ${ }^{2}$ \\ ${ }^{I}$ Department of Neurosurgery, Chung-Ang University College of Medicine, Seoul, Korea \\ ${ }^{2}$ Department of Orthopedic and Trauma, Quang Nam Central General Hospital, Quang Nam, Vietnam
}

Objective: In Korea, direct lateral interbody fusion (DLIF) was started since 2011, using standard cage $\left(6^{\circ}\right.$ lordotic angle, $18 \mathrm{~mm}$ width). Recently, a new wider cage with higher lordotic angle $\left(12^{\circ}, 22 \mathrm{~mm}\right)$ was introduced. The aim of our study is to compare the clinical and radiologic outcomes of the two cage types.

Methods: We selected patients underwent DLIF, 125 cases used standard cages (standard group) and 38 cases used new cages (wide group). We followed them up for more than 6 months, and their radiological and clinical outcomes were analyzed retrospectively. For radiologic outcomes, lumbar lordotic angle (LLA), segmental lordoic angle (SLA), disc angle (DA), foraminal height change $(\mathrm{FH})$, subsidence and intraoperative endplate destruction (iED) were checked. Clinical outcomes were compared using visual analog scale (VAS) score, Oswestry disability index (ODI) score and complications.

Results: LLA and SLA showed no significant changes postoperatively in both groups. DA showed significant increase after surgery in the wide group $(p<0.05)$, but not in the standard group. Subsidence was significantly lower in the wide group $(p<0.05)$. There was no difference in clinical outcomes between the two groups. Additional posterior decompression was done more frequently in the wide group. Postoperative change of foraminal height was significantly lower in the wide group $(p<0.05)$. The iED was observed more frequently in the wide group $(p<0.05)$ especially at the anterior edge of cage. Conclusion: The new type of cage seems to result in more DA and less subsidence. But indirect foraminal decompression seems to be less effective than standard cage. Intraoperative endplate destruction occurs more frequently due to a steeper lordotic angle of the new cage.

Key Words: DLIF $\cdot$ Cage $\cdot$ Type $\cdot$ Outcome

\section{INTRODUCTION}

Direct lateral interbody fusion (DLIF) is the method of minimal invasive lumbar interbody fusion where a trans-psoas approach is made using a tubular retractor system. It is also termed as lateral trans-psoas lumbar interbody fusion or extreme lateral lumbar interbody fusion. Currently, DLIF is usually performed with specialized instruments (Medtronic Sofamor Danek, Inc., Memphis, TN, USA) in Korea. Since first report by MeAfee PC et al in $1998^{23)}$, it has been widely performed

- Received: August 15, 2014 - Revised: August 22, 2014

- Accepted: September 3, 2014

Corresponding Author: Seung Won Park, MD, PhD

Department of Neurosurgery, Chung-Ang University Hospital, 102 Heukseong-ro,

Dongjak-gu, Seoul 156-755, Korea

Tel: +82-2-6299-3190, Fax: +82-2-821-8409

E-mail: nspsw@cau.ac.kr

®This is an Open Access article distributed under the terms of the Creative

Commons Attribution Non-Commercial License (http://creativecommons.org/ licenses/by-nc/3.0/) which permits unrestricted non-commercial use, distribution, and reproduction in any medium, provided the original work is properly cited. for degenerative lumbar disease such as spinal stenosis, spondylolisthesis, scoliosis, and multi-level degenerative disc disease $^{7,17}$. It was first introduced to Korea in May of 2011 and it has been actively used at several institutes. Due to its lateral approach method and structural characteristics of cage, DLIF has several advantages comparing to other approaches like posterior lumbar interbody fusion (PLIF), transforaminal lumbar interbody fusion (TLIF) or anterior lumbar interbody fusion (ALIF). First, various important anatomical structures including back muscles, anterior and posterior longitudinal ligaments and facet joint are preserved ${ }^{25,29}$. Second, a minimal invasive approach can reduce the intraoperative bleeding or surgical time ${ }^{4)}$. As compared with the ALIF, the risks of injuries to peritoneum, bowels, and great vessels are relatively lower ${ }^{18)}$. As compared with the TLIF, the DLIF cage, with higher profile and wider width, can effectively raise the disc height and decompress neural foramen indirectly ${ }^{25)}$. DLIF cage is also known to be effective for restoration of coronal and sagittal balance in the patients with lumbar degenerative kyphosis (LDK) or scoliosis ${ }^{4,16,20,30)}$. The standard type of DLIF cage has a $6^{\circ}$ of lordotic angle and $18 \mathrm{~mm}$ of width (Fig. 1). 


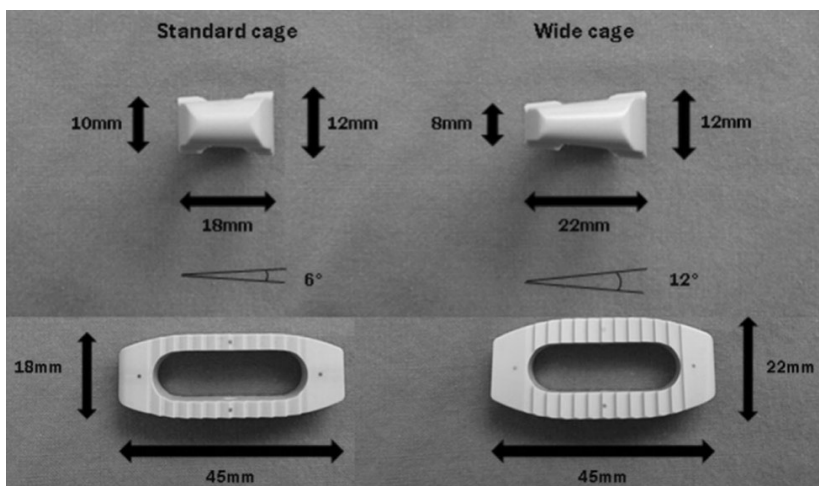

Fig. 1. Comparing standard cage ( $6^{\circ}$ lordotic angle, $18 \mathrm{~mm}$ width) with wide cage ( $12^{\circ}$ lordotic angle, $22 \mathrm{~mm}$ width). Difference of height between anterior and posterior part of the cage are 2 $\mathrm{mm}$ (standard cage) and $4 \mathrm{~mm}$ (wide cage).

According to the papers using the standard type of cage, insufficient restoration of lumbar lordotic angle for regional or global sagittal alignment and subsidence were indicated constantly ${ }^{1,12,32)}$. This arises from a lower lordotic angle $\left(6^{\circ}\right)$ and relatively narrow width of the standard type DLIF cage. A new DLIF cage with higher lordotic angle $\left(12^{\circ}\right)$ and wider width $(22 \mathrm{~mm})$ seemed to overcome the limitations of the standard cage, which had been launched in Korea two years ago (Fig. 1). Although there had been several papers about the wide cage ${ }^{19,22)}$, they seemed not to discuss pitfalls of the new cage thoroughly. Moreover, there was no report about the new cage in Korea yet. The current study was conducted to investigate the clinical and radiological outcomes of the new wide cage comparing to those of the standard cage.

\section{MATERIALS AND METHODS}

\section{Patient Selection}

The current study examined 163 patients who underwent DLIF between May 2011 and January 2014. The operation was performed by a single surgeon. We performed a retrospective analysis of the postoperative clinical and radiological outcomes.

\section{Indications and Surgical Candidates}

Surgery was performed for the levels from T12 and L5. Surgical indications were spinal stenosis, spondylolisthesis ( $\leq$ grade 2), degenerative scoliosis, and infectious spondylitis. We excluded the patients with retroperitoneal adhesion due to prior surgery, severe spondylolisthesis ( $\geq$ grade 3 ), severe rotational deformity, or active infection.

\section{Surgical Technique}

Under general endotracheal anesthesia, patients were placed in a true right lateral position. By bending the bed, the space between the rib and iliac crest was maximally extended. The disc space of index level should be confirmed with C-arm. Flexion of left hip and knee is helpful to relax psoas muscle of the approach side. After draping, the target level was confirmed using C-arm again. The dissection site was marked on the skin. Using a No. 10 blade, an approximately $3 \mathrm{~cm}$ transverse skin incision was made. Thereafter, the three layers of abdominal muscles were dissected one by one. When the retroperitoneal fat was exposed, the peritoneum and retroperitoneal fat were dissected away anteriorly from the posterior abdominal wall using an index finger. Then, the target disc under the psoas muscle was palpated. Tubular retractors were secured at the target disc space. Intraoperative EMG monitoring was done during the procedures. After discectomy, the endplate preparation was done to expose the bony endplates. Although autologous bone graft is the most ideal fusion material for fusion ${ }^{10)}$, it was hard to harvest autologous bone during DLIF because of its minimal invasive approach. Currently, recombinant bone morphogenetic protein-2 (rh-BMP2) is widely used for bone fusion ${ }^{28,33)}$ in many countries. But the material is not available in Korea due to the strict policy of Korean government. We used demineralized bone matrix (DBM) as a fusion material. Following the insertion of the cage, the wound was closed by layers.

\section{Radiological Analysis}

Whole spine standing X-ray studies were pre- (1 day before surgery) and post-operatively (6 days after surgery) to measure lumbar lordotic angle (LLA), segmental lordotic angle (SLA) and disc angle (DA) (Fig. 2). LLA was measured by the Cobb angle formed between the lower endplate of $\mathrm{L} 1$ and the upper endplate of S1. SLA was measured by the angle between the upper endplate of the upper vertebra and the lower endplate of the lower vertebra at the corresponding level. In addition, DA was measured by the angle between the two endplates at the operated disc level. Post-operative change of foraminal height $(\mathrm{FH})$ was measured based on the mean height of bilateral foramens on lumbar spine oblique X-ray films. Subsidence was measured as the change in the distance between the upper endplate of upper vertebra and the lower endplate of lower vertebra of index level using lumbar spine lateral X-ray films, comparing the distances checked immediate postoperatively to those at 6 months postoperatively. Postoperative change in the distance more than $2 \mathrm{~mm}$ was considered to be a mean- 


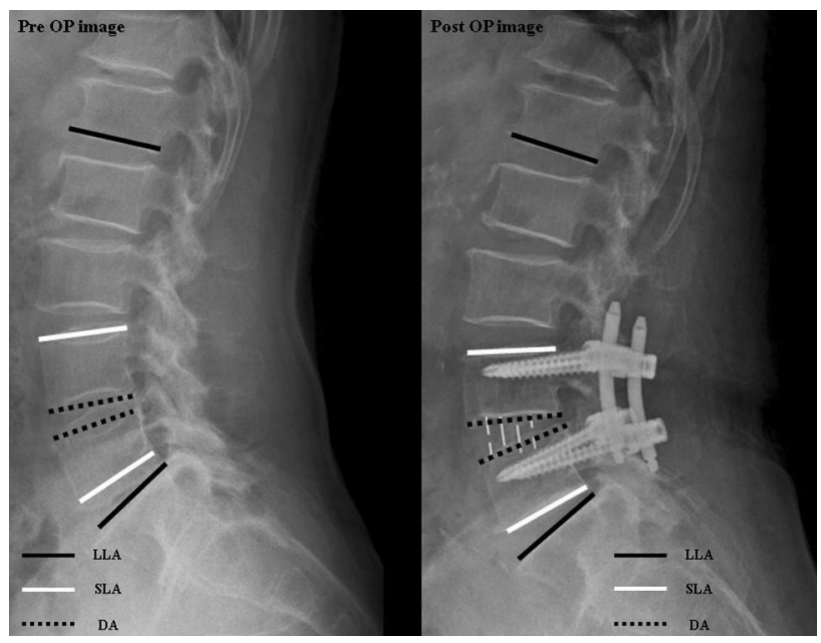

Fig. 2. Lumbar lordotic angle (LLA), segmental lordotic angle $(\mathrm{SLA})$, disc angle (DA) and foraminal height (FH). LLA is defined as a Cobb angle formed between the lower endplate of $\mathrm{Ll}$ and the upper endplate of S1. SLA is defined as an angle between the upper endplate of the upper vertebra and the lower endplate of the lower vertebra at the corresponding level. DA is defined as an angle between the upper endplate of the upper vertebra and the lower endplate of the lower vertebra at the corresponding level.

ingful subsidence ${ }^{14,24)}$ (Fig. 3). Intraoperative endplate destruction (iED) was checked on the immediate postoperative simple $\mathrm{X}$-ray films, usually around the anterior and posterior sharp edges of DLIF cage.

\section{Clinical Outcomes}

We checked pre- and post-operative (6 months after surgery) visual analog scale (VAS) scores and Oswestry disability index (ODI). We also evaluated surgical complications.

\section{Statistical Analysis}

Student T-test, $\chi^{2}$ test, and multiple logistic regression analysis were used for statistical analysis. $\mathrm{p}<0.05$ was considered to be a statistical significance.

\section{RESULTS}

\section{Demographic Data}

Of the 163 patients, 125 and 38 were assigned to the standard group and wide group, respectively. Mean age and maleto-female ratio were 60.51-14.51 years and 50:75 in the standard group, and 63.29-9.99 years and 12:26 in the wide group $(\mathrm{p}>0.05)$. T-scores of bone mineral density $(\mathrm{BMD})$ were

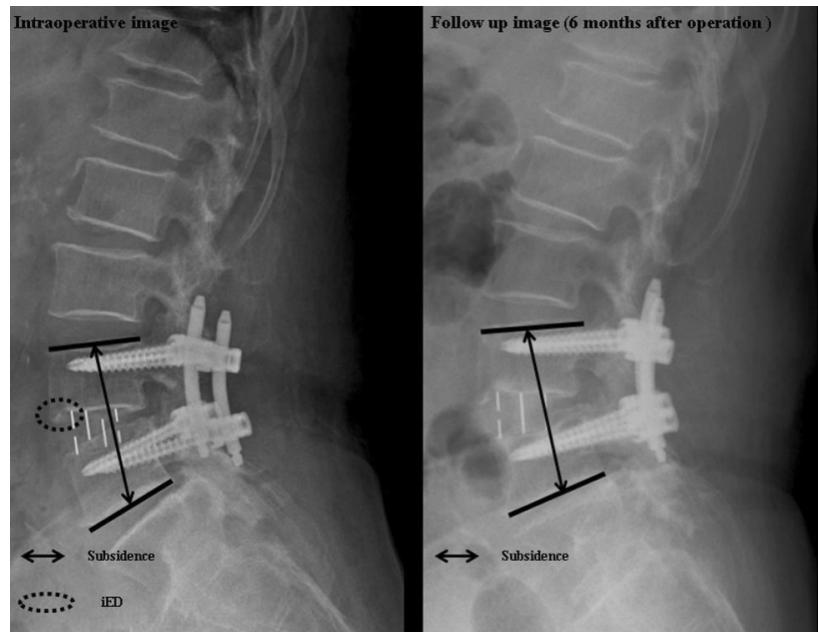

Fig. 3. Subsidence and intraoperative endplate destruction (iED). Subsidence is measured as the change in the distance between the upper endplate of upper vertebra and the lower endplate of lower vertebra of index level using lumbar spine lateral X-ray films, comparing the distances checked immediate postoperatively to those at 6 months postoperatively. iED is checked on the immediate postoperative simple X-ray films, usually around the anterior and posterior sharp edges of DLIF cage.

Table 1. Demographic, surgical data

\begin{tabular}{lccc}
\hline \hline & $\begin{array}{c}\text { Standard group } \\
(\mathrm{n}=125)\end{array}$ & $\begin{array}{c}\text { Wide group } \\
(\mathrm{n}=38)\end{array}$ & $\mathrm{p}$ value \\
\hline Age & $60.51 \pm 14.51$ & $63.29 \pm 9.99$ & 0.263 \\
& $(20-88)$ & $(39-77)$ & \\
Sex (M:F) & $50: 75$ & $12: 26$ & 0.349 \\
BMD (T-score) & -0.82 & -0.88 & 0.39 \\
Number of levels & & & \\
1 level & $88(70.4 \%)$ & $24(63.2 \%)$ & 0.399 \\
2 levels & $28(22.4 \%)$ & $10(26.3 \%)$ & 0.617 \\
3 levels & $8(6.4 \%)$ & $3(7.9 \%)$ & 0.748 \\
4 levels & $1(0.8 \%)$ & $1(2.6 \%)$ & 0.369 \\
Operation time (min) & & & \\
Lateral per 1 level & $39.7 \pm 16.2$ & $38.5 \pm 23.1$ & 0.104 \\
Posterior decompression & $(21-63)$ & $(19-61)$ & \\
\hline
\end{tabular}

-0.82 and -0.88 in the standard and wide groups, respectively $(p>0.05)$ (Table 1). Total numbers of fusion levels were 172 in the standard group and 57 in the wide group.

\section{Surgical Data}

In the standard group, there were 88 (70.4\%) patients with single level, 28 (22.4\%) patients with 2 levels, 8 (6.4\%) pa- 
tients with 3 levels and $1(0.8 \%)$ patient with 4 levels fusion (Table 1). In the wide group, these values were 24 (63.2\%), $10(26.3 \%), 3(7.9 \%)$ and $1(2.6 \%)$ in the corresponding or$\operatorname{der}(\mathrm{p}>0.05)$. The mean operation time for 1 level of DLIF was 39.7-16.2 minutes in the standard group and 38.5-23.1 minutes in the wide group $(\mathrm{p}>0.05)$. The proportion of the patients who underwent additional posterior decompression at the time of surgery was $50.4 \%(63 / 125)$ in the standard group and $84.2 \%(32 / 38)$ in the wide group $(\mathrm{p}<0.001)$.

\section{Radiological Outcomes}

Pre- and postoperative mean LLA in the standard group were $39.5 \pm 18.3^{\circ}$ and $44.5 \pm 18.8^{\circ}(\mathrm{p}>0.05)$ (Table 2). Preand postoperative mean LLA in the wide group were $40.6 \pm$ $9.8^{\circ}$ and $46.2 \pm 9.6^{\circ}(\mathrm{p}>0.05)$. Pre- and postoperative SLA were $9.1 \pm 4.4^{\circ}$ and $10.1 \pm 5.2^{\circ}$ in the standard group, and $8.9 \pm 3.5^{\circ}$ and $12.7 \pm 6.1^{\circ}$ in the wide group $(\mathrm{p}>0.05)$. Preand postoperative DA was $6.5 \pm 4.5^{\circ}$ and $8.1 \pm 5.1^{\circ}$ in the standard group ( $>00.05)$, and $6.9 \pm 3.9^{\circ}$ and $10.1 \pm 7.8^{\circ}$ in the wide group $(\mathrm{p}<0.05)$. There was no significant difference in the preoperative DA's between the two groups. But the postoperative DA was significantly higher in the wide group comparing to that of standard group $(p<0.05)$ (Table 2$)$. The postoperative change in the $\mathrm{FH}$ was significantly lower in the wide group $(2.7 \pm 1.2 \mathrm{~mm})$ comparing to that of the standard group $(4.3 \pm 2.8 \mathrm{~mm})(\mathrm{p}<0.05)$. Subsidence was significantly less in the wide group $(1.2 \pm 0.5 \mathrm{~mm})$ comparing to that of the standard group $(4.4 \pm 2.5 \mathrm{~mm})(\mathrm{p}<0.05)$ (Table 3$)$. The

Table 2. Radiologic data

\begin{tabular}{lccc}
\hline & Standard group & Wide group & $p$ value \\
\hline LLA $\left(^{\circ}\right)$ & & & \\
Pre op & $39.5 \pm 18.3$ & $40.6 \pm 9.8$ & 0.085 \\
Post op & $44.5 \pm 18.8$ & $46.2 \pm 9.6$ & 0.011 \\
p value & 0.123 & 0.207 & \\
SLA ( ${ }^{\circ}$ ) & & & \\
Pre op & $9.1 \pm 4.4$ & $8.9 \pm 3.5$ & 0.378 \\
Post op & $10.1 \pm 5.2$ & $12.7 \pm 6.1$ & 0.28 \\
p value & 0.444 & 0.215 & \\
DA ( ${ }^{\circ}$ ) & & & \\
Pre op & $6.5 \pm 4.5$ & $6.9 \pm 3.9$ & 0.088 \\
Post op & $8.1 \pm 5.1$ & $10.1 \pm 7.8$ & 0.042 \\
p value & 0.073 & 0.013 & \\
FH change (mm) & $4.3 \pm 2.8$ & $2.7 \pm 1.2$ & 0.039 \\
Cage height (mm) & $12.9 \pm 1.3$ & $13.6 \pm 1.2$ & 0.002 \\
\hline${ }^{*}$ LLA: lumbar lordotic angle & & \\
${ }^{*}$ SLA: segmental lordotic angle & & \\
${ }^{*}$ DA: disc angle & & & \\
${ }^{*}$ FH: foraminal height & &
\end{tabular}

number of the patients with iED was significantly higher in the wide group $(16,42.1 \%)$ comparing to that of standard group $(31,24.8 \%)(p<0.05)$ (Table 3). The iED was occurred more frequently at the anterior edge of cage in the wide group, whereas at the posterior edge of cage in the standard group $(\mathrm{p}<0.05)$ (Table 3).

\section{Clinical Outcomes}

VAS scores were significantly decreased postoperatively from $6.1 \pm 2.4$ to $2.3 \pm 1.2$ in the standard group $(p<0.001)$, and from $5.9 \pm 1.3$ to $2.1 \pm 0.9$ in the wide group $(\mathrm{p}<0.001)$ (Table 4). ODI scores were also improved postoperatively from $41.4 \pm 15.0 \%$ to $12.5 \pm 4.4 \%$ in the standard group ( $\mathrm{p}<$ 0.001 ), and from $48.0 \pm 15.1 \%$ to $14.5 \pm 7.6 \%$ in the wide group $(\mathrm{p}<0.001)$ (Table 4). But there was no statistical significance in the changes of VAS and ODI scores between the groups. There were 17 cases of psoas muscle symptom (13.6\%),

Table 3. Subsidence, iED

\begin{tabular}{lccc}
\hline \hline & Standard group & Wide group & $\mathrm{p}$ value \\
\hline Subsidence $(\mathrm{mm})$ & $4.4 \pm 2.5$ & $1.2 \pm 0.5$ & 0.011 \\
$2 \mathrm{~mm}<$ & $18(14.4 \%)$ & $3(7.9 \%)$ & 0.281 \\
iED* & $31(24.8 \%)$ & $16(42.1 \%)$ & 0.042 \\
Anterior part of cage & $15(48.4 \%)$ & $13(81.3 \%)$ & 0.037 \\
\hline
\end{tabular}

"Intraoperative endplate destruction

Table 4. Clinical data and complications

\begin{tabular}{|c|c|c|c|}
\hline & $\begin{array}{l}\text { Standard } \\
\text { group }\end{array}$ & $\begin{array}{l}\text { Wide } \\
\text { group }\end{array}$ & $\mathrm{p}$ value \\
\hline \multicolumn{4}{|l|}{ VAS score } \\
\hline Pre op & $6.1 \pm 2.4$ & $5.9 \pm 1.3$ & 0.069 \\
\hline Post op & $2.3 \pm 1.2$ & $2.1 \pm 0.9$ & 0.412 \\
\hline$p$ value & $<0.001$ & $<0.001$ & \\
\hline \multicolumn{4}{|l|}{ ODI score (\%) } \\
\hline Pre op & $41.4 \pm 15.0$ & $48.0 \pm 15.1$ & 0.204 \\
\hline Post op & $12.5 \pm 4.4$ & $14.5 \pm 7.6$ & 0.362 \\
\hline $\mathrm{p}$ value & $<0.001$ & $<0.001$ & \\
\hline \multicolumn{4}{|l|}{ Complication } \\
\hline Psoas muscle injury & $17(13.6 \%)$ & $6(15.8 \%)$ & 0.735 \\
\hline Genitofemoral nerve injury & $5(4.0 \%)$ & $3(7.9 \%)$ & 0.396 \\
\hline $\begin{array}{l}\text { Lateral femoral cutaneous } \\
\text { nerve injury }\end{array}$ & $3(2.4 \%)$ & $2(5.3 \%)$ & 0.382 \\
\hline Bowel perforation & $1(0.8 \%)$ & $0(0.0 \%)$ & 0.964 \\
\hline Infection & $1(0.8 \%)$ & $0(0.0 \%)$ & 0.964 \\
\hline Lumbosacral plexus injury & $0(0.0 \%)$ & $0(0.0 \%)$ & 0.556 \\
\hline Cage migration & $0(0.0 \%)$ & $0(0.0 \%)$ & 0.556 \\
\hline
\end{tabular}


5 genitofemoral nerve injury (4.0\%), 3 lateral femoral cutaneous nerve symptom (2.4\%), 1 bowel perforation ( $0.8 \%)$, and 1 infection (0.8\%) in the standard group. In the wide group, there were 6 cases of psoas muscle symptom (15.8\%), 3 genitofemoral nerve injury (7.9\%), and 2 lateral femoral cutaneous nerve symptom (5.3\%). There was no significant difference in the postoperative complications between the two groups (Table 4).

\section{DISCUSSION}

DLIF can use a large interbody cage less invasively as compared with other types of lumbar interbody fusion techniques $^{2)}$. Indirect increase of foraminal height, less subsidence, and considerable restoration of lumbar lordotic angle were reported to be important advantages of DLIF procedure ${ }^{5,25)}$. However, some papers reported that there was still considerable rate of subsidence, and the effect of DLIF on making lumbar lordotic angle seemed to be insufficient for correction of sagittal imbalance ${ }^{12)}$. To solve the problems, a new type of cage (wide cage) had been developed with higher lordotic angle $\left(12^{\circ}\right)$ and wider width $(22 \mathrm{~mm})$ comparing to those of standard cage $\left(12^{\circ}\right.$ and $\left.8 \mathrm{~mm}\right)$ (Fig. 1). We recently have experienced a series of patients underwent DLIF surgery using the new cage. In this paper, we tried to compare radiological and clinical outcomes between the standard and wide cages.

There were several papers reporting the effect of DLIF for correction of coronal alignment without detailed investigation for the effect of DLIF on lumbar sagittal angle ${ }^{3,13,31,32)}$. Therefore, we checked sagittal angles including LLA, SLA and DA. According to our data, DLIF did not seem to have significant effect on LLA. This finding seems to be related with short segment fixation in most of our cases. This is similar to the reports of other papers ${ }^{1,31,32)}$, where they pointed the insufficient effect of short segment DLIF on LLA. But significant increase of DA by the new cage seemed to suggest the possible usefulness of DLIF with the high angle cage in the surgery of sagittal imbalance which is still in controversy. Despite of significant increase of DA by the new cage, SLA did not show significant change. The discrepancy between SLA and DA seems to arise from the anatomic characteristics of vertebral body. The downward angle of the upper endplate of upper vertebral body, making anterior wedging shape, looks like the cause of less SLA comparing to the increased DA. So, we think the DA can reflect the actual change of lumbar sagittal angle by insertion of interbody cage.

Kepler CK et al and Oliveira L et $\mathrm{al}^{15,25)}$ measured the area of foraminal height, and reported effective indirect decompression of neural foramen by DLIF. FH was also reported to be increased effectively by DLIF more than ALIF or TLIF ${ }^{11)}$. However, the neural foraminal area can be decreased during rod compression to make more lordotic angle. There was a significantly less increase of $\mathrm{FH}$ by the wide cage as compared with those by the standard cage, suggesting the wide cage has a lower degree of indirect foraminal decompression. This might be due to the structural differences between the two cages. The standard cage has $6^{\circ}$ lordotic angle resulting in a $2 \mathrm{~mm}$ height difference between the anterior and posterior parts of the cage (Fig. 1). But, the posterior height of the wide cage is $4 \mathrm{~mm}$ less than the anterior height because of its high angle, $12^{\circ}$ (Fig. 1). As a result, posterior disc height and foraminal height can be smaller by using the new cage than the standard cage. To compensate the disadvantages, we tried to use the wide cage with higher profile or to perform an additional posterior decompression. It was the reason of the increased use of higher profile cage and more frequent posterior decompression in the group using the new cage. However, the use of higher profile cage in the wide group seems to be related with the increase intraoperative endplate destruction. The intraoperative endplate destruction occurs more frequently at the anterior edge of the new cage, whereas the standard cage tends to destruct endplate more frequently at its posterior edge.

Our data showed that subsidence can be decreased significantly by using wide cage. This might be due to a larger footprint of the wide cage, which can cover more marginal area of vertebral body providing stronger mechanical support and more resistance to subsidence ${ }^{21)}$. The thicker wall of the wide cage seems to be another reason of higher mechanical resistance to load (Fig. 1).

There was no significant difference in the VAS and ODI scores between the standard and wide groups, which is similar to other reports ${ }^{8,931)}$. The long term clinical outcome of DLIF was not significantly different from that of $\mathrm{TLF}^{26}$. Complication rates were also similar in both groups like as other reports ${ }^{6,27,32)}$.

The limitations of the current study are the relatively small number of patients and short follow-up period with the wide group. Most of our cases were operated in a short segment which is insufficient to interpret the effect of the new cage for deformity correction especially in sagittal imbalance. It seems to be needed a long term study with more number of patients and long level fusion cases in the future.

\section{CONCLUSION}

The new DLIF cage has a higher lordotic angle and a larger width comparing to those of the pre-existing standard cage. The characteristic shape of the new cage has advantages for 
making more lordotic angle at the index disc level and reducing subsidence. But, at the same time, it seems to have some weak points such as an increased risk of intraoperative endplate destruction and a possible risk of neural foraminal stenosis due to its steep angle.

\section{REFERENCES}

1. Acosta Jr FL, Liu J, Slimack N, Moller D, Fessler R, Koski $\mathrm{T}$ : Changes in coronal and sagittal plane alignment following minimally invasive direct lateral interbody fusion for the treatment of degenerative lumbar disease in adults: a radiographic study: Clinical article. Journal of Neurosurgery: Spine 15:92-96, 2011

2. Anand N, Baron EM, Thaiyananthan G, Khalsa K, Goldstein TB: Minimally invasive multilevel percutaneous correction and fusion for adult lumbar degenerative scoliosis: a technique and feasibility study. Journal of Spinal Disorders \& Techniques 21: 459-467, 2008

3. Anand N, Rosemann R, Khalsa B, Baron EM: Mid-term to longterm clinical and functional outcomes of minimally invasive correction and fusion for adults with scoliosis. Neurosurgical focus 28:E6, 2010

4. Aygün H, Çakar A, Atilla HA, Aytekin MN, Irlayıcı FB, Çelik $\mathrm{R}$, et al: Early results of the Patients who undergo Direct lateral interbody fusion technique due to degenerative Scoliosis. Novel Science International Journal of Medical Sciences 2, 2013

5. Buranakarl T, Jaisanuk K: The new Lumbar Spinal Fusion technique: Minimally Invasive Trans-psoas approach (Direct Lateral Interbody Fusion $\left(\mathrm{DLIF}^{\circledR}\right)$ ) and a preliminary report of clinical and radiographic success in Bangkok Spine Academy. Bangkok Medical Journal 4, 2014

6. Cummock MD, Vanni S, Levi AD, Yu Y, Wang MY: An analysis of postoperative thigh symptoms after minimally invasive transpsoas lumbar interbody fusion: clinical article. Journal of Neurosurgery: Spine 15:11-18, 2011

7. Dakwar E, Cardona RF, Smith DA, Uribe JS: Early outcomes and safety of the minimally invasive, lateral retroperitoneal transpsoas approach for adult degenerative scoliosis. Neurosurgical focus 28:E8, 2010

8. Deukmedjian AR, Le TV, Baaj AA, Dakwar E, Smith DA, Uribe JS: Anterior longitudinal ligament release using the minimally invasive lateral retroperitoneal transpsoas approach: a cadaveric feasibility study and report of 4 clinical cases: Laboratory investigation. Journal of Neurosurgery: Spine 17:530-539, 2012

9. Elowitz E, Yanni D, Chwajol M, Starke R, Perin N: Evaluation of indirect decompression of the lumbar spinal canal following minimally invasive lateral transpsoas interbody fusion: radiographic and outcome analysis. Minimally Invasive Neurosurgery 54:201, 2011

10. Helm GA, Sheehan JM, Sheehan JP, Jane Jr JA, diPierro CG, Simmons NE, et al: Utilization of type I collagen gel, demineralized bone matrix, and bone morphogenetic protein- 2 to enhance autologous bone lumbar spinal fusion. Journal of Neurosurgery 86:93-100, 1997

11. Hsieh PC, Koski TR, O'Shaughnessy BA, Sugrue P, Salehi S,
Ondra S, et al: Anterior lumbar interbody fusion in comparison with transforaminal lumbar interbody fusion: implications for the restoration of foraminal height, local disc angle, lumbar lordosis, and sagittal balance, 2007

12. Johnson R, Valore A, Villaminar A, Comisso M, Balsano M: Pelvic parameters of sagittal balance in extreme lateral interbody fusion for degenerative lumbar disc disease. Journal of Clinical Neuroscience 20:576-581, 2013

13. Karikari IO, Nimjee SM, Hardin CA, Hughes BD, Hodges TR, Mehta AI, et al: Extreme lateral interbody fusion approach for isolated thoracic and thoracolumbar spine diseases: initial clinical experience and early outcomes. Journal of Spinal Disorders \& Techniques 24:368-375, 2011

14. Kepler CK, Sharma AK, Huang RC: Lateral transpsoas interbody fusion (LTIF) with plate fixation and unilateral pedicle screws: a preliminary report. Journal of Spinal Disorders \& Techniques 24:363-367, 2011

15. Kepler CK, Sharma AK, Huang RC, Meredith DS, Girardi FP, Cammisa Jr FP, et al: Indirect foraminal decompression after lateral transpsoas interbody fusion: Clinical article. Journal of Neurosurgery: Spine 16:329-333, 2012

16. Kim JS, Lee HS, Shin DA, Kim KN, Yoon DH: Correction of Coronal Imbalance in Degenerative Lumbar Spine Disease Following Direct Lateral Interbody Fusion (DLIF). Korean J Spine 9:176-180, 2012

17. Knight RQ, Schwaegler P, Hanscom D, Roh J: Direct lateral lumbar interbody fusion for degenerative conditions: early complication profile. Journal of Spinal Disorders \& Techniques 22: 34-37, 2009

18. Laws CJ, Coughlin DG, Lotz JC, Serhan HA, Hu SS: Direct lateral approach to lumbar fusion is a biomechanically equivalent alternative to the anterior approach: an in vitro study. Spine 37:819-825, 2012

19. Le TV, Baaj AA, Dakwar E, Burkett CJ, Murray G, Smith DA, et al: Subsidence of polyetheretherketone intervertebral cages in minimally invasive lateral retroperitoneal transpsoas lumbar interbody fusion. Spine 37:1268-1273, 2012

20. Le TV, Vivas AC, Dakwar E, Baaj AA, Uribe JS: The effect of the retroperitoneal transpsoas minimally invasive lateral interbody fusion on segmental and regional lumbar lordosis. The Scientific World Journal 2012, 2012

21. Lowe TG, Hashim S, Wilson LA, O'Brien MF, Smith DA, Diekmann MJ, et al: A biomechanical study of regional endplate strength and cage morphology as it relates to structural interbody support. Spine 29:2389-2394, 2004

22. Marchi L, Abdala N, Oliveira L, Amaral R, Coutinho E, Pimenta L: Radiographic and clinical evaluation of cage subsidence after stand-alone lateral interbody fusion: Clinical article. Journal of Neurosurgery: Spine 19:110-118, 2013

23. McAfee PC, Regan JJ, Geis WP, Fedder IL: Minimally invasive anterior retroperitoneal approach to the lumbar spine: emphasis on the lateral BAK. Spine 23:1476-1484, 1998

24. Mummaneni P, Tu T, Ziewacz J, Akinbo O, Deviren V, Mundis G: The role of minimally invasive techniques in the treatment of adult spinal deformity. Neurosurgery Clinics of North America 24:231, 2013

25. Oliveira L, Marchi L, Coutinho E, Pimenta L: A radiographic assessment of the ability of the extreme lateral interbody fusion 
procedure to indirectly decompress the neural elements. Spine 35:S331-S337, 2010

26. Parker SL, Adogwa O, Paul AR, Anderson WN, Aaronson O, Cheng JS, et al: Utility of minimum clinically important difference in assessing pain, disability, and health state after transforaminal lumbar interbody fusion for degenerative lumbar spondylolisthesis: Clinical article. Journal of Neurosurgery: Spine 14:598-604, 2011

27. Patel VC, Park DK, Herkowitz HN: Lateral Transpsoas Fusion: Indications and Outcomes, 2012

28. Pimenta L: The use of rh-BMP2 in standalone eXtreme Lateral Interbody Fusion $\left(\mathrm{XLIF}^{\circledR}\right)$ : clinical and radiological results after 24 months follow-up, 2010

29. Potter BK, Freedman BA, Verwiebe EG, Hall JM, Polly Jr DW, Kuklo TR: Transforaminal lumbar interbody fusion: clinical and radiographic results and complications in 100 consecutive patients. Journal of Spinal Disorders \& Techniques 18:337-346, 2005
30. Sama AA: Lateral Interbody Decompression and Fusion: Which Side to Approach From?, in Minimally Invasive Spinal Deformity Surgery: Springer, pp245-253, 2014

31. Sharma AK, Kepler CK, Girardi FP, Cammisa FP, Huang RC, Sama AA: Lateral lumbar interbody fusion: clinical and radiographic outcomes at 1 year: a preliminary report. Journal of Spinal Disorders \& Techniques 24:242-250, 2011

32. Tormenti MJ, Maserati MB, Bonfield CM, Okonkwo DO, Kanter AS: Complications and radiographic correction in adult scoliosis following combined transpsoas extreme lateral interbody fusion and posterior pedicle screw instrumentation. Neurosurgical Focus 28:E7, 2010

33. Vaidya R, Sethi A, Bartol S, Jacobson M, Coe C, Craig JG: Complications in the use of rhBMP-2 in PEEK cages for interbody spinal fusions. Journal of Spinal Disorders \& Techniques 21:557-562, 2008 